\title{
A Preliminary Investigation of Smart Rural Water Distribution Systems in the Gambia
}

\author{
Will Ingram ${ }^{1}$, Leen Saeb ${ }^{1}$, Seyed Sadr ${ }^{1}$, Rob Hygate ${ }^{2}$, Fayyaz Ali Memon${ }^{1}$ \\ ${ }^{1}$ Centre for Water Systems, University of Exeter, Exeter, UK \\ ${ }^{2}$ eWATERpay, Newbury, UK \\ Email: *wi211@exeter.ac.uk
}

How to cite this paper: Ingram, W., Saeb, L., Sadr, S., Hygate, R. and Memon, F.A. (2018) A Preliminary Investigation of Smart Rural Water Distribution Systems in the Gambia. Journal of Water Resource and Protection, 10, 395-407.

https://doi.org/10.4236/jwarp.2018.104021

Received: January 31, 2018

Accepted: April 15, 2018

Published: April 18, 2018

Copyright $\odot 2018$ by authors and Scientific Research Publishing Inc. This work is licensed under the Creative Commons Attribution International License (CC BY 4.0).

http://creativecommons.org/licenses/by/4.0/

\begin{abstract}
An estimated one-third of water points in rural sub-Saharan Africa are non-functioning at any one time because of lack of upkeep. Communities are left without access to clean drinking water and this has multiple knock-on developmental impacts. An innovative pre-payment and Internet-of-Things enabled "e-Tap" based water technology and management system cycles revenue back into operation and maintenance and collects accurate and real-time data on consumption and tap failures. This has been operational in the Gambia since April 2016. Preliminary research has begun on evaluating this innovation. Technical tests were conducted to examine the efficiency of the e-Tap under varying conditions. Water use trends were then analysed by using the cloud-collected data transmitted from operational e-Taps. Further, baseline surveys to investigate social parameters were undertaken on 20 user households. This exploratory research shows the e-Taps to work efficiently in the laboratory and the Gambia with negligible failures, and to reduce distances users must travel for clean water and time they spend collecting.
\end{abstract}

\section{Keywords}

Innovation, Rural Water Supply, Smart Technology, The Gambia, e-Tap

\section{Introduction}

The challenge of rural water supply in sub-Saharan Africa is well-documented. Globally, $89 \%$ of the world's population used at least a basic drinking water service, defined by the WHO/UNICEF Joint Monitoring Programme as no more than a 30 minute round trip to collect water from an improved source. However, this proportion falls to $58 \%$ in sub-Saharan Africa [1]. The region is making the slowest progress towards improved rural water supply [2]. This lack of progress 
is compounded by broader trends such as population growth, urbanisation, economic inequality and poverty, along with increasing environmental pressures on water resources such as climate change and pollution [3] [4] [5] [6]. Access to sustainable and clean rural water supply is required to reduce the burden of disease, general health, gender equality, economic development, food security, education and poverty reduction. Estimates of the proportion of non-functioning handpumps across sub-Saharan Africa at any time range from $10 \%$ to $67 \%$, with an average of around one third, caused mostly by a lack of operation and maintenance of water infrastructure (O\&M) [7] [8] [9].

There is agreement in the recent literature that the unsustainability of the predominant "community management" model of rural water supply is the main reason for lack of O\&M [10] [11]. Communities do not have sufficient capacity, finances or support. There is also a lack of timely and accurate data on water points. New thinking and innovation is required to meet the Sustainable Development Goals (SDGs) Target 6.1: "by 2030, achieve universal and equitable access to safe and affordable drinking water for alp'. There have been some efforts to develop and implement technologies that report rural handpump non-functionality in real-time by using information communication technologies [12]. Two technologies reported in the literature are internet of things enabled [13] [14]. These have focused on handpumps, and not standpipes of water distribution systems. Additionally, there has been limited focus on how such technologies can improve sustainability of rural water supply in the long term with regards to the systemic context, for instance the use of reported data for water use trend analysis. No such technology implementation or research has been undertaken in the Gambia.

A pre-payment sustainable rural water supply system using "e-Taps" (described below) has been developed and operational since April 2016. The effectiveness of the e-Taps has not yet been investigated or reported on in the literature. The present study aims to test the technical operation of the e-Taps and evaluate their usage by water users in the context of rural sub-Saharan Africa. In order to do this, a series of laboratory based technical tests were conducted, usage data transmitted from operating e-Taps were analysed and users were surveyed on their usage patterns. The study was conducted with a particular focus on the Gambia.

Further versions of the e-Tap have been developed since the research reported here was conducted, and are currently being investigated.

\section{Methodology}

\subsection{Outline of the e-Tap Based System}

The e-Taps allow for continuous clean water access from standpipes by close contact with a user-specific electronic token, using Near Field Communication (NFC) technology. Water flows from the e-Tap when the token is placed in contact with the e-Tap, and until it is removed, as shown in Figure 1. The tokens 


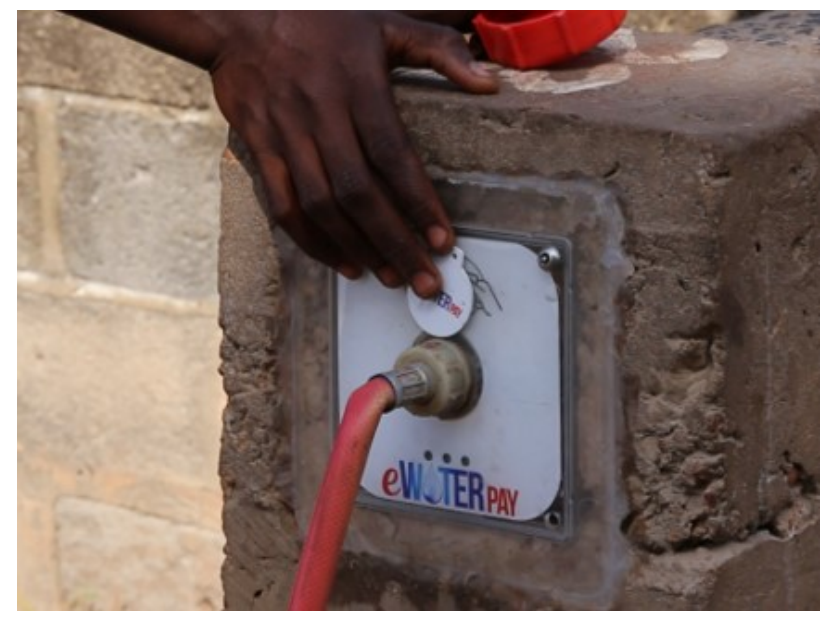

Figure 1. e-Tap and token in contact releasing water.

contain editable and readable user-specific data. They are pre-loaded by users with affordable water credits by contactless pay technology from a local vendor, at the time worth approximately 0.5 pence per 20 litres used. The majority of funds collected are then used for operation and maintenance (O\&M) of e-Taps that break, which is carried out by locally employed technicians. Internet of Things (IoT) connectivity provides instant notification of e-Tap failures via cloud data management and a dashboard interface of allowing rapid O\&M and real-time tracking of revenue, usage and flow-rates. A photovoltaic array provides power. This study focuses on version 1.0 of the e-Tap operational in the Gambia in from April to July 2016.

\subsection{Overview of the Gambia and Villages under Study}

The WHO/UNICEF Joint Monitoring Programme [1] scored access to water in the Gambia as "high risk" ( $10 \%-20 \%$ of the population without access to improved drinking water sources). The World Resources Institute scores groundwater stress as "low" [15]. Disparity between rural and urban water supply is high and emblematic of sub-Saharan Africa; $32 \%$ of the rural population in the Gambia were without at least basic drinking water service in 2015, as illustrated in Figure 2. This compares to around 12\% of the urban population. Figure 3 demonstrates that in 2015 the majority of the improved drinking water supply in rural communities in the Gambia is from piped sources, which is an improvement from 2000 where the majority was non-piped. Data from 2015 is used as it provides the most recent accurate assessment, and still serves to illustrate the comparison with the year 2000 .

Four villages with 52 e-Taps (Kerr Lein, 3 e-Taps; Jafai Koto, 7 e-Taps; Jarreng, 28 e-Taps; and Brikama $\mathrm{Ba}, 18$ e-Taps) with seasonal average-temperature ranges of $23^{\circ} \mathrm{C}-30^{\circ} \mathrm{C}$ have been the subject of our preliminary investigations.

\subsection{Technical Testing}

The e-Tap performs under variable conditions in the environment outside the 


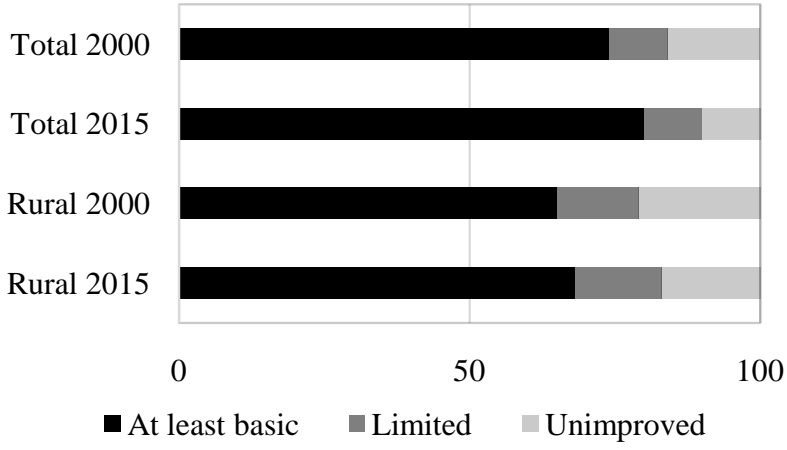

Figure 2. Percentage of Gambian population using different drinking water service levels in the Gambia. Adapted from Joint Monitoring Programme [1].

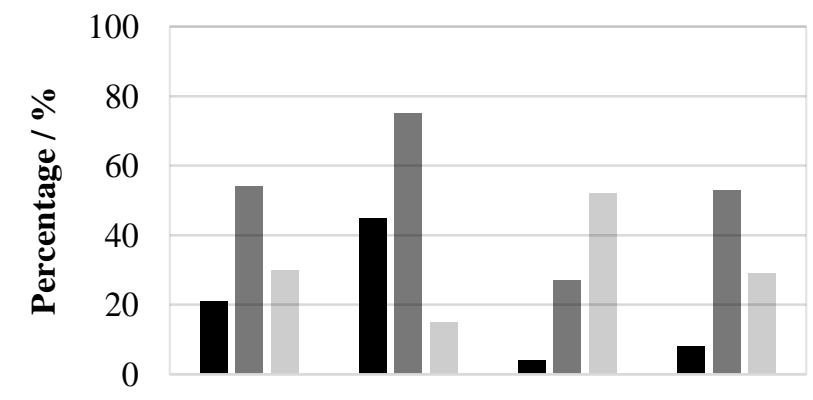

Total 2000 Total 2015 Rural 2000 Rural 2015

- Accessible on premises $\quad$ Piped Non-piped

Figure 3. Percentage of total and rural Gambia populations using improved drinking water supply. Adapted from Joint Monitoring Programme [1].

laboratory. These are likely to differ from the conditions that the manufacture's specifications were measured in, which are outlined in Table 1. The e-Tap interior design is illustrated in Figure 4. To investigate how reliable the performance of the e-Taps is under variable conditions, a number of tests were conducted. These are described as below.

Pressure flow test: A pressure flow curve was plotted using flow tests through the e-Tap (see Figure 4) at varying pressures of $0.1-1.8$ bar. These were compared against the manufacturing specification curve and available field observations, to define where e-Taps function efficiently.

Durability test: Average e-Tap use frequency per household in the four study villages was found to be 7 times per day. Average use of each e-Tap per day was 50. Therefore the e-Taps are subject to multiple on-off switching events and must therefore demonstrated durability to these. Multiple on-off switching events were tested at varying time intervals $(10,15,30$ and 60 minutes) at different pressures ( 0.6 and 1.8 bar), and time to failure was investigated. Testing at different pressures was considered to represent changing conditions outside of the laboratory. 
Table 1. Manufacturer's specifications of the e-Tap version 1.0.

\begin{tabular}{cc}
\hline Pressure range & $0-2.8$ bar \\
Temperature range & $0^{\circ} \mathrm{C}-60^{\circ} \mathrm{C}$ \\
Fluid temperature & $25^{\circ} \mathrm{C}$ \\
Flow direction & Unidirectional \\
Flow & $1-151 \cdot \mathrm{min}^{-1}$ \\
Inlet diameter & $3 / 4$ inch \\
Outlet diameter & 1 inch \\
Power Supply & $5-28$ voltage DC \\
\hline
\end{tabular}

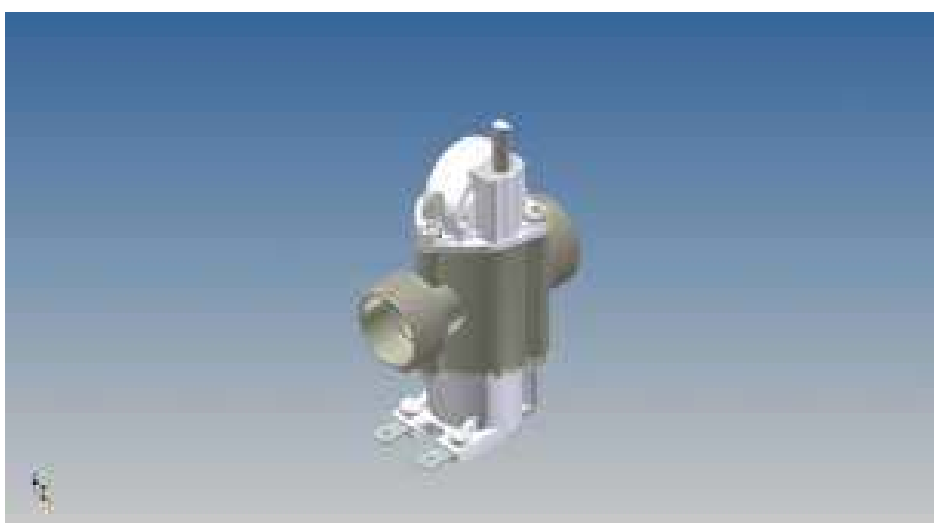

Figure 4. CAD illustration from the e-Tap interior.

Sand retention test: In two of the villages, around $5 \%$ of e-Taps were previously observed to malfunction because of sand particles infiltrating from the elevated water tank or via piping. e-Tap failure time was investigated when continuously pumping water loaded with $50 \mathrm{~g}$ and $100 \mathrm{~g}$ of $1-2 \mathrm{~mm}$ diameter (mean $1.37 \mathrm{~mm}$ ) sand particles at 0.6 bar across different flow rates through the e-Tap.

\subsection{Water Usage Pattern Analysis}

Water usage data was collected via the cloud system mentioned in Section 2.1 between 1st April 2016 and 31st July 2016 from 52 operational e-Taps, with 925 households registered with electronic tokens. These were used to investigate usage patterns. Identity of the token owner, amount of water dispensed, the date and time, and the e-Tap identification were collected. To supplement this data, a survey was conducted across 10 households in each of Brikama Ba (18 e-Taps) and Jarreng (28 e-Taps) to investigate usage patterns on a household and token-holder level. 24 households were sampled and 20 surveys of sufficient quality were selected. Households were chosen at random from a wider sample of confirmed users of e-Taps. Households were questioned on their source of water, time and frequency of collection, amount collected, distance travelled and household members who collect. Water quality parameters of smell, taste and colour were questioned, and questions exploring affordability aspects, user 
friendliness and reliability of the e-Tap were included. Anonymised information on gender, age, number of children, income and literacy was recorded alongside.

\section{Results and Discussion}

\subsection{Technical Testing Results}

Pressure flow test: The pressure curve, plotted using average values from five tests per pressure, fits well with the manufactures specifications, as seen in Figure 5. This is unsurprising and demonstrates uniformity between e-Taps. Increased flow rates from field observations may be from different measurement methodologies practiced in the field that constantly give higher values. The alignment with laboratory measurements at 0.1 bar and high increases at 0.6 bar and 1.8 bar, however, indicate outliers. More replicable measurements are needed to infer conclusions. Insignificant leakage from the e-Tap's outlet connection was measured over the length of the experiment, showing $3 \mathrm{ml}$ at $0.5 \mathrm{bar}$ and $14 \mathrm{ml}$ at 1 bar. Therefore, secure fitting is important in the field.

Durability test: It was reported in the household survey that no e-Taps in the Gambia failed during the four months of the study in any of the study villages. In the technical testing, no e-Tap failure was observed at any pressure. Average values of number of on-off switching events that could be conducted across different time intervals are reported in Table 2, none of which saw e-Tap failure,

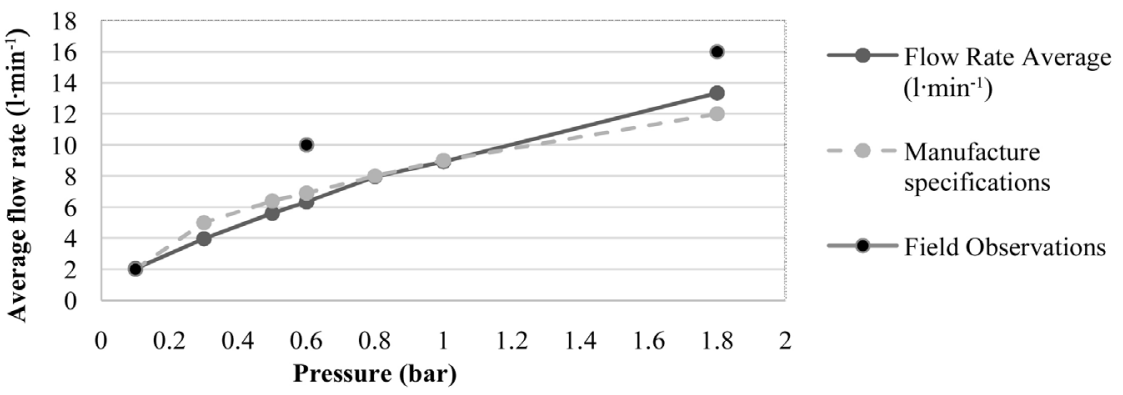

Figure 5. Pressure flow test curve against manufacture specifications and field observations.

Table 2. On-off switching events conducted without failures.

\begin{tabular}{ccc}
\hline Pressure (bar) & Time intervals (min) & $\begin{array}{c}\text { Average number of on-off switching events } \\
\text { conducted in time intervals (no failure observed) }\end{array}$ \\
\hline 0.6 & 10 & 308 \\
1.8 & 10 & 101.75 \\
0.6 & 15 & 239 \\
1.8 & 15 & 151.5 \\
0.6 & 30 & 523.25 \\
1.8 & 30 & 302 \\
0.6 & 60 & 3112 \\
1.8 & 60 & 1008 \\
\hline
\end{tabular}


therefore demonstrating high reliability over a high number of potential usage events.

Sand retention test: No operational failure of the e-Tap was observed at any flow rate at either mass of sand particles (50 and $100 \mathrm{~g}$ ) throughout the continuous pumping through the e-Tap. A minor decrease in outlet flow rate was observed at lower inlet flow rates indicating reduced capacity under high sand particle load, which requires further investigation. Understanding and implementing a solution to sand particle infiltration would reduce water collection time and potentially improve water quality.

The e-Taps are noted to have worked robustly and efficiently. They are durable to multiple use. However, this can only be reported for preliminary laboratory based technical testing. Further technical testing under real-life conditions is required to verify these findings.

\subsection{Documented e-Tap Technical Challenges in the Gambia}

The e-Taps work almost universally effectively in the Gambia over the study period, however some minor failures have been observed. In cases where the electric power drops below 5 volts, the outlet was observed to remain opened and water is dispensed without activation from a token and therefore wasted. Drops in voltage were observed, mainly caused by the solar array lacking sufficient direct sunlight. Additionally, water has been observed to reach the e-Tap's circuit board either through seepage or condensation, rendering them inoperable. Conformal coating spray that forms isolation on the circuit boards is a potential solution for this.

\subsection{Documented e-Tap Technical Challenges in the Gambia}

The comprehensiveness of accurate and timely data collection was observed. Overall withdrawal volumes across the selected time period are reported in $\mathrm{Ta}$ ble 3.

Per capita withdrawal falls below what has been recommended as a basic water requirement for human activities of $501 \cdot \mathrm{capita}^{-1} \cdot \mathrm{day}^{-1}$ [16]. Table 4 shows that there was greater withdrawal (litres.person ${ }^{-1} \cdot$ month $^{-1}$ ) observed in Brikama $\mathrm{Ba}$. It is hypothesised that the population of Brikama $\mathrm{Ba}$ use more water for the functions of drinking, cooking, bathing and other daily uses due to increased awareness of the value of using clean potable water. It was reported to the investigators that $67 \%$ of Brikama Ba's population attended school in comparison to Jarreng, where more than $55 \%$ of the population lack education.

Table 3. Withdrawal volumes between $1^{\text {st }}$ April and $31^{\text {st }}$ July 2016.

\begin{tabular}{cc}
\hline & Average withdrawal \\
\hline Across 52 e-Taps & $572,5201 \cdot \mathrm{month}^{-1}$ \\
Per household & $620 \mathrm{l} \cdot \mathrm{month}^{-1}$ \\
Per capita & $12.9-18.8 \mathrm{l} \cdot$ day $^{-1}$ \\
\hline
\end{tabular}


Table 4. Comparison of water withdrawal between the villages of Jarreng and Brikama Ba.

\begin{tabular}{cccc}
\hline & e-Taps & $\begin{array}{c}\text { Number of } \\
\text { token owners }\end{array}$ & Withdrawal (litres.person ${ }^{-1} \cdot$ month $^{-1}$ ) \\
\hline Jarreng & 28 & 640 & 55 \\
Brikama Ba & 18 & 270 & 79 \\
\hline
\end{tabular}

\subsection{Variability of Withdrawal}

Monthly and daily withdrawal variability was plotted in Figure 6. July was selected as the month that shows most variability in precipitation and temperature at the start of the rainy season. High and low withdrawal rates correlate with the weather in the region on the day. The 11th July 2016 is reported to have had relatively high temperatures requiring high water withdrawal rates, while the 30th July 2016 had relatively high levels of precipitation thus reducing water withdrawal requirements.

Hourly withdrawal variability was plotted in Figure 7. Despite peak times in the morning and evening, there is variability on an individual token-owner level, and further analysis of individual's water collection patterns would reveal dependency throughout the day, therefore demonstrating the importance of a durable and reliable water supply.

\subsection{Household Level}

In the survey sample, the average size of households is reported to be 10.4, with 5 adults and 5 children ( $<12$ years). Average expenditure per household on potable water is 307 Dalasi (4.84 GBP) per month from an average income of 4900 Dalasi (77.30 GBP) per month. Household collection demographics show that women collect the majority of water, with girls and to a lesser extent boys also participating, as reported in Table 5. This correlates with the pattern across sub-Saharan Africa where women and girls are responsible for collecting water in 8 out of 10 households with water sources away from the home. This is lengthy and takes time from education or other productive work, and also impacts long-term health [1]. It is estimated that women in many developing countries walk for an average of about $6 \mathrm{~km}$ each day to collect water, and spend up to $40 \%$ of their daily calorific intake in carrying water [17] [18].

Average distance between two e-Taps is $300 \mathrm{~m}$, which is significantly less than previous distances that women must travel to collect. Thus, e-Taps have the potential to impact women's development and gender equality [18]. It is also reported that $55.5 \%$ of the survey respondents could not use the e-Taps and top up credits easily without training. Both findings require further investigation.

\subsection{Discussion on how to Improve e-Tap Effectiveness}

There are 48 local handpumps in Jarreng which are used apart from e-Taps. Around $20 \%$ of these were reported as failed at the time of the study. The success of the e-Tap compares favourably to this background situation. 

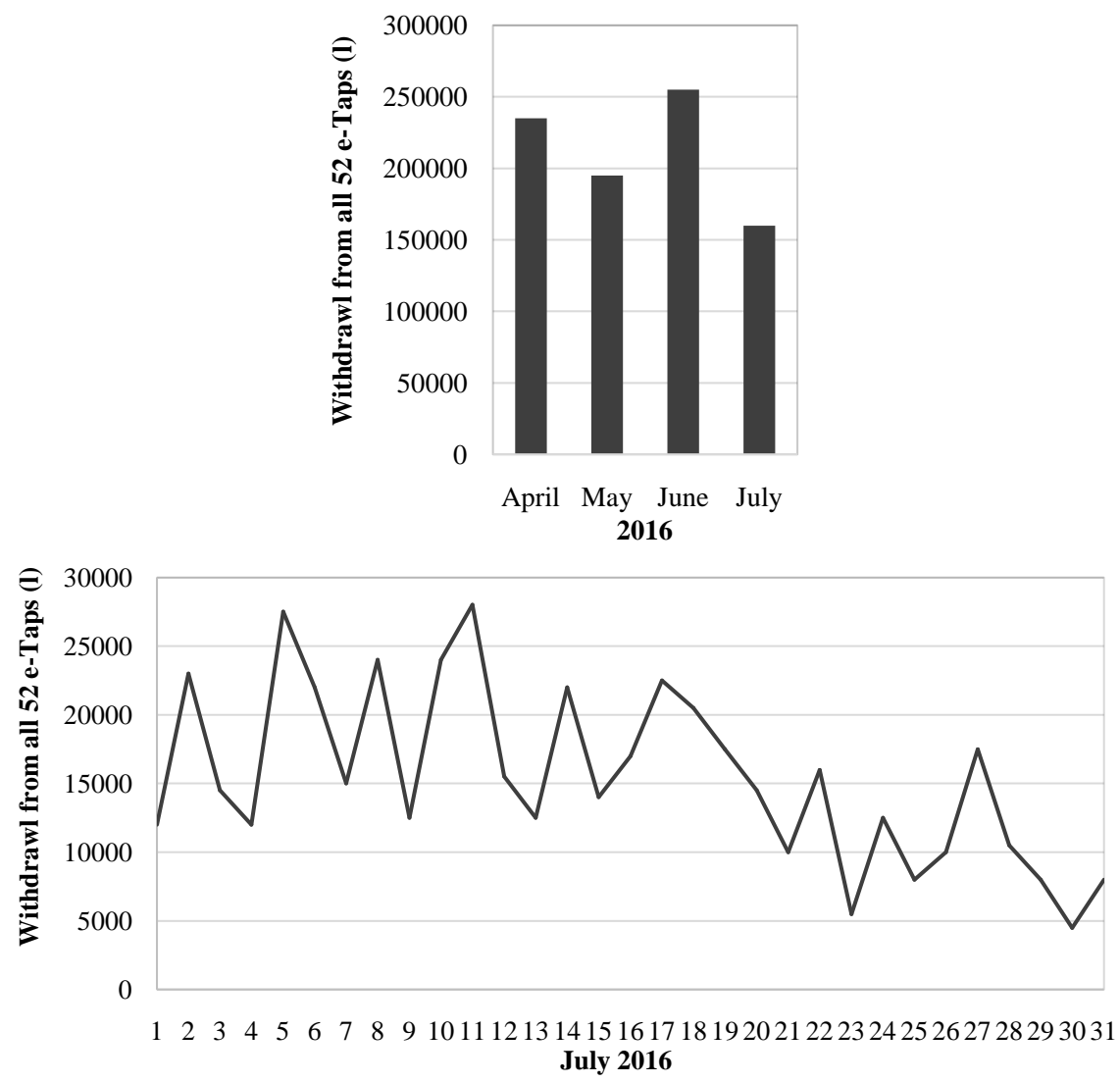

Figure 6. Withdrawal variability over the months April to July 2016, and over July.

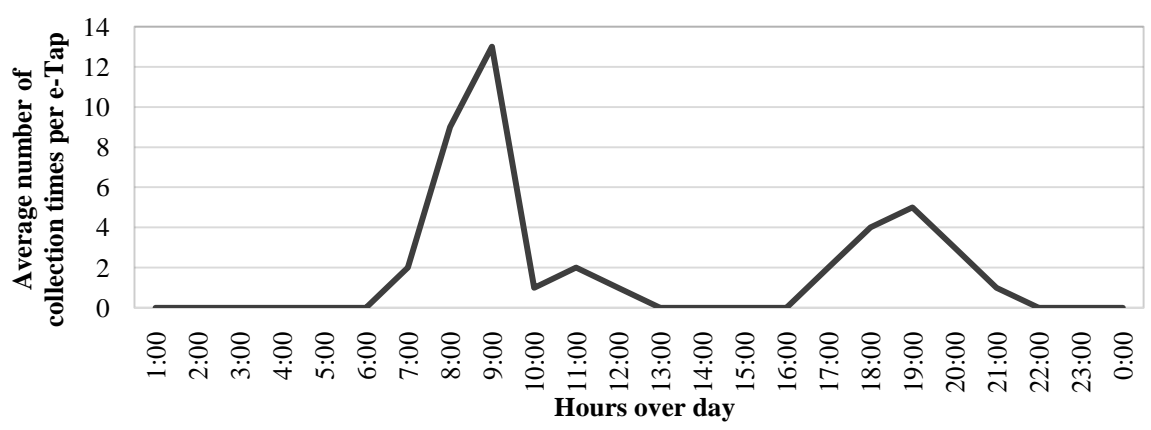

Figure 7. Hourly withdrawal variability of 28 e-Taps over one day in Jarreng.

Table 5. Distribution of household water collectors.

\begin{tabular}{cc}
\hline Woman, adult & $66.6 \%$ \\
Man, adult & $0.00 \%$ \\
Girl, child & $22.2 \%$ \\
Boy, child & $11.1 \%$ \\
\hline
\end{tabular}

Version 1.0 of the e-Tap is shown to work robustly and reliably over the study period, both in varying laboratory conditions and in the field. Future research on effectiveness should focus more on sustainability in the longer-term, perhaps over years or decades, rather than remedial technical trouble-shooting. This 
could include predictive modelling techniques alongside an integration of research on the developmental and environmental context. Considering that the fundamental failure of rural water supply in sub-Saharan Africa is the unsustainability of infrastructure [8] [9], this should form a key part of further research and development. The technical aspects of the e-Taps only partly influence sustainability, however. Rural water supply in sub-Saharan Africa is a complex system with multiple inputs and interactions, and social, economic, political, cultural and environmental factors will all influence e-Tap sustainability. These must be fully understood in order to maximise long-term effectiveness of e-Taps.

Variability in usage patterns over the study period indicates that longer term fluctuations may be significant, which may impact long-term effectiveness or uptake by communities. For instance, long wet periods or periods of reduced income may reduce the need or affordability of e-Taps to an extent where they lose financial viability and therefore become unsustainable for the communities. This will require longer-term research. Additionally, a key component of a sustainability analysis should be an investigation of how external and systemic factors influence e-Tap use and effectiveness. Increased environmental (e.g. precipitation) variability [5] is likely to impact the variability in usage patterns. This is partly demonstrated here by correlation of withdrawal volumes with daily weather. For instance, a year of very low rainfall as a result of regional climatic changes could see an increase in e-Tap water withdrawal for the year, which could lead to expended coverage of e-Taps across neighbouring communities as a result of increased revenues. However if the following year sees heavily increased rainfall, these newly installed e-Taps could not be used enough to be financially viable, and therefore be unsustainable.

The e-Tap and novel management system has the potential to provide a new model of rural water supply that moves away from failed community management, so long as this is implemented in a sustainable manner with full consideration of the system it operates within. This will require more holistic and long-term research.

\section{Summary and Opportunities}

The effective use of the e-Taps and their durability are noted. The technology has made a significant positive impact on rural water access in The Gambia, and has therefore high potential across sub-Saharan Africa more generally. This preliminary study demonstrates key areas where the e-Tap based systems will require further research. This is important because as more e-Taps are becoming operational, there will be significantly more data available for analysis across different regions, requiring new analytical techniques. If relevant user ID information is collected, data mining and other big data techniques could be considered [19]. Such techniques could provide information on who is using the e-Taps, specifically the time, volumes and frequency of usage by different users 
over a study group. Geographical information could also be integrated, for instance the distance travelled of specific groups of users to e-Taps, or variations across different regions. This could inform the development of e-Tap based systems to better serve communities. This information would have to remain anonymised for privacy reasons. As seen in Figure 6, there is some observed alignment of water withdrawal patterns with weather. Therefore, meteorological forecasts may be useful for predicting future e-Tap use and therefore benefit planning of O\&M. For example, this future planning could in turn benefit sustainability, and move beyond previous work on similar technologies. This could perhaps utilise machine-learning techniques that integrate meteorological forecasts with the e-Tap based system's dashboard.

The negligible failure rate in the laboratory based technical testing conducted here suggests that rigorous evaluation of the e-Taps in real-life conditions instead would be most representative. However, far more on-off switching events were recorded without any failures than would be done in the village setting, over the reported time periods. Data on individual e-Taps, perhaps with a combined analysis of different e-Tap use over a day, would allow for a more location-oriented enquiry. Likewise, data on variation of e-Tap used by each token owner could allow for analysis of user preference and positioning of e-Taps. Drops in voltage require testing to understand how this can be avoided in the villages. Further research will require a synthesis of technical testing and socioeconomic study to better understand sustainable and up-scaled implementation of e-Taps in the complex system that comprises rural water supply in sub-Saharan Africa.

Some potential errors are evident throughout the study. The technical questions are only assessed with very preliminary tests. A number of variables could not be assessed, and the number of repeat experiments was limited. Furthermore, the laboratory conditions negated some important factors that are present in the field. While errors do not apply to the remote collection and reporting of water use data, the data analysis can be queried further. More accurate meteorological data would provide stronger evidence for the causality of changes in water use with changing temperature. These were not available retrospectively, and further research will aim to collect relevant extraneous data concurrently. The limited number of household surveys meant that any statistical analysis on household data was limited. Overall, however, these studies serve as an adequate preliminary evaluation. The technology reviewed demonstrably benefits efforts to improve rural water supply in sub-Saharan Africa.

\section{Disclaimer}

The findings presented here are based on limited research and the authors do not take responsibility for their use directly or indirectly. Further versions of the e-Tap have been developed since the research was conducted (www.ewaterpay.com). Lessons learnt from the reported study have been incor- 
porated in the design of improved versions of the e-Tap. Further lab- and field-based testing is planned and findings will be reported accordingly.

\section{References}

[1] WHO and UNICEF (2017) Progress on Drinking Water, Sanitation and Hygiene: 2017 Update and SDG Baselines. World Health Organization and the United Nations Children's Fund, Geneva. https://washdata.org/

[2] Hope, R. (2015) Is Community Water Management the Community's Choice? Implications for Water and Development Policy in Africa. Water Policy, 17, 664-678. https://doi.org/10.2166/wp.2014.170

[3] Sadoff, C.W, Hall, J.W., Grey, D., Aerts, J.C.J.H., Ait-Kadi, M., Brown, C., Cox, A., Dadson, S., Garrick, D., Kelman, J., McCornick, P., Ringler, C., Rosegrant, M., Whittington, D. and Wiberg, D. (2015) Securing Water, Sustaining Growth: Report of the GWP/OECD Task Force on Water Security and Sustainable Growth. University of Oxford, Oxford, UK.

[4] UNESCO (2015) United Nations World Water Assessment Programme. The United Nations World Water Development Report 2015: Water for a Sustainable World. United Nations Educational, Scientific and Cultural Organization, Paris.

[5] Cisneros, J., Oki, B.E., Arnell, T., Benito, N.W., Cogley, G., Döll, J.G., Jiang, P. and Mwakalila, T. (2014) Freshwater Resources. Intergovernmental Panel on Climate Change (IPCC), Climate Change 2014: Impacts, Adaptation, and Vulnerability. Contribution of Working Group II to the Fifth Assessment Report of the IPCC. Cambridge University Press, Cambridge, UK, New York, USA, 229-269.

[6] Grey, D. and Sadoff, C.W. (2007) Sink or Swim? Water Security for Growth and Development. Water Policy, 9, 545-571. https://doi.org/10.2166/wp.2007.021

[7] Tincani, L., Ross, I., Zaman, R., Burr, P., Mujica, A., Ensink, J. and Evans, B. (2015) Improving Value for Money and Sustainability in WASH Programmes (VFM-WASH). Regional Assessment of the Operational Sustainability of Water and Sanitation Services in Sub-Saharan Africa. Oxford Policy Management, Oxford.

[8] RWSN (2009) Myths of the Rural Water Supply Sector. Perspectives No. 4, Rural Water Supply Network Executive Steering Committee, St Gallen. http://www.rwsn.ch

[9] Baumann, E. (2006) Do Operation and Maintenance Pay? Waterlines, 25, 10-12. https://doi.org/10.3362/0262-8104.2006.033

[10] Hutchings, P., Chan, M.Y., Cuadrado, L., Ezbakhe, F., Mesa, B., Tamekawa, C. and Franceys, R. (2015) A Systematic Review of Success Factors in the Community Management of Rural Water Supplies over the Past 30 Years. Water Policy, 17, 963-983. https://doi.org/10.2166/wp.2015.128

[11] Moriarty, P., Smits, S., Butterworth, J. and Franceys, R. (2013) Trends in Rural Water Supply: Towards a Service Delivery Approach. Water Alternatives, 6, 329-349.

[12] Pearce, J., Dickinson, N. and Welle, K. (2014) Technology, Data, and People: Opportunities and Pitfalls of Using ICT to Monitor Sustainable WASH Service Delivery. In: Shouten, T. and Smits, S., Eds., Infrastructure to Services. Trends in Monitoring Sustainable Water, Sanitation and Hygiene Services, Practical Action Publishing, Rugby, UK, 85-108.

[13] Hope, R., Thomson, P., Koehler, J., Foster, T. and Thomas, M. (2014) From Rights to Results in Rural Water Services-Evidence from Kyuso, Kenya. Water Programme, Working Paper 1, University of Oxford, Oxford, UK. 
[14] Nagel, C., Beach, J., Iribagiza, C. and Thomas, E.A. (2015) Evaluating Cellular Instrumentation on Rural Handpumps to Improve Service Delivery-A Longitudinal Study in Rural Rwanda. Environmental Science \& Technology, 49, 14292-14300. https://doi.org/10.1021/acs.est.5b04077

[15] WRI (2017) AQUEDUCT, Water Risk Atlas. http://www.wri.org/our-work/project/aqueduct/

[16] Gleick, P.H. (1996) Basic Water Requirements for Human Activities: Meeting Basic Needs. Water International, 21, 83-92. https://doi.org/10.1080/02508069608686494

[17] UNEP (2010) Africa Water Atlas. United Nations Environment Programme, Division of Early Warning and Assessment, Nairobi. https://na.unep.net/atlas/africaWater/downloads/africa_water_atlas.pdf

[18] UNFPA (2002) Water: A Critical Resource. United Nations Population Fund, New York. http://lwvlaplata.org/files/unfpa_water_1_.pdf

[19] Stuart, E., Samman, E., Avis, W. and Berliner, T. (2015) The Data Revolution: Finding the Missing Millions. Overseas Development Institute, London. 